University of Massachusetts Amherst

ScholarWorks@UMass Amherst

1994

\title{
Comparison of the Maximum Sensitivity of Different Flow Injection Manifold Configurations: Alternating Variable Search Optimization of the Iron(II)/1,10-Phenanthroline System
}

SJ Chalk

University of Massachusetts Amherst

Julian Tyson

University of Massachusetts Amherst

Follow this and additional works at: https://scholarworks.umass.edu/chem_faculty_pubs

Part of the Analytical Chemistry Commons

\section{Recommended Citation}

Chalk, SJ and Tyson, Julian, "Comparison of the Maximum Sensitivity of Different Flow Injection Manifold Configurations: Alternating Variable Search Optimization of the Iron(II)/1,10-Phenanthroline System" (1994). Analytical Chemistry. 1386.

Retrieved from https://scholarworks.umass.edu/chem_faculty_pubs/1386 


\title{
Comparison of the Maximum Sensitivity of Different Flow Injection Manifold Configurations: Alternating Variable Search Optimization of the Iron(II)/1,10-Phenanthroline System
}

\author{
Stuart J. Chalk and Jullan F. Tyson \\ Department of Chemistry, University of Massachusetts, Amherst, Massachusetts 01003-0035
}

\begin{abstract}
Three manifold configurations used in flow injection analysis were optimized for maximum sensitivity for the spectrophotometric determination of iron(II) by complexation with 1,10-phenanthroline. The parameters of flow rate(s), injected volume, manifold length, and reagent concentration were studied for single, double, and reverse single line flow injection manifolds. All the manifolds produced maximum sensitivity when the dispersion coefficient (measured from the product profile) was less than 1.1. All the flow injection configurations were of comparable sensitivity, with that of the reverse configuration being slightly higher than those of the other two. The double line configuration gave the lowest detection limit (10 $\mathrm{n} \mathrm{mL}^{-1}$ ) because of the absence of refractive index peaks.
\end{abstract}

A flow injection (FI) manifold for a determination based on the measurement of a reaction product formed as a result of on-line chemical reaction must be designed to achieve mixing between reagent and analyte such that reagent is in sufficient excess at the maximum of the profile to ensure the greatest degree of reaction. However, dilution of the sample should be minimized so as to avoid an unnecessary loss in sensitivity. The design of a FI manifold can be considered as the search for optimum dispersion characteristics.

The dispersion coefficient is governed by the hydrodynamic characteristics of the manifold. The major factors are (a) laminar flow (which produces a parabolic distortion of the initial boundaries), (b) radial diffusion, (c) radial mixing at confluence points (should the manifold contain these), and (d) secondary flow processes. The latter include radial circulation induced by coiling of the flow conduits, vortex shedding caused by step changes in tube diameter, small regions of turbulent flow produced by sharp angled bends, and surge in flow produced when the injection valve is switched.

The difficulties of describing these processes accurately are well recognized, and the design of manifolds is based on the expected trends in dispersion behavior as a function of the various parameters over which there is some control. These include flow rate, volume injected, extent of coiling, use of packed reactors, etc. These trends have been summarized as a set of rules by Ruzicka and Hansen. ${ }^{1}$ Both these authors and those of another of the first texts to appear, Valcarcel and

(1) Ruzicka, J.; Hansen, E. H. Flow Injection Analysis, 2nd ed.; Wiley: New York, 1988.
Luque de Castro, ${ }^{2}$ state that the merging stream manifold has a higher sensitivity than the single line manifold on the basis that the former design overcomes a limitation of the single line manifold, namely, the formation of double peaks when the volume injected is increased. Both of these texts also support the notion that the reverse FI configuration, in which the reagent is injected into the sample as carrier stream, has an inherent higher sensitivity. The term reverse FI (rFI) was first used by Johnson and Petty, ${ }^{3}$ who applied the procedure to the determination of phosphate in seawater and concluded that "by the simple change of injecting the reagent, rather than the sample, the sensitivity can be increased relative to conventional FIA".

These general conclusions have been challenged by Tyson ${ }^{4,5}$ on the basis of some simple calculations for the performance of FI manifolds in which all the dispersion processes were modeled by plug flow through a single well-stirred tank reactor, with instantaneous radial mixing at the confluence point in the case of the double line manifold. In the first of these publications, it was calculated that the same sensitivity should be obtained from both the single line system and the double line system, and in the second of these publications, the discussion was extended to the rFI case when it was shown that this also would give rise to the same sensitivity. It is recognized that if the aim of the method development is to obtain the best detection limits, then high sensitivity is only one factor to be considered, as detection limit is both a function of sensitivity and noise. For practical reasons associated with factors other than the slope of the calibration plot, the best performance was obtained with a double line manifold. These practical limitations will also be discussed in this paper.

There would be appear to be little in the original literature concerning the verification of the "conventional wisdom" of the manifold design required for high sensitivity. Rios et al. ${ }^{6}$ reported a comparison of normal and reverse manifolds for the determination of cyanide in which the sensitivity of the rFI method was significantly poorer than that of the normal FI (nFI) procedure (single line manifold). The authors commented that this finding was "at variance with previous observations" and cited results for the determination of copper

(2) Valcarcel, M.; Luque de Castro, M. D. Flow Injection Analysis, Principles and Applications; Ellis Horwood: Chichester, UK, 1987; p 397.

(3) Johnson, K. S.; Petty, R. L. Anal. Chem. 1982, 54, 1185.

(4) Tyson, J. F. Quim. Anal. 1989, 8, 171

(5) Tyson, J. F. Analyst 1990, 115, 587

(6) Rios, A.; Luque de Castro, M. D.; Valcarcel, M. Talanta 1984, 31, 673. 
by a catalytic fluorometric method ${ }^{7}$ for which the sensitivity was 4 times higher for the rFI method than for the nFI method. However, it is clear that optimization of the nFI method did not involve a search for maximum sensitivity, but some compromise figure of merit involving both peak height and throughput. The previous discussion of the relative sensitivities of the normal and reverse procedure ${ }^{5}$ showed that if the dispersion coefficient of the manifold was $>2$ (as is the case for most manifolds), then simply reversing the sample and reagent would give rise to an increase in sensitivity. In a recent survey paper concerning "sensitivity in flow injection analysis", the conventional notions concerning the relative sensitivity of manifold designs were reiterated. ${ }^{8}$

It seems self evident that (a) as the maximum sensitivity is achieved by minimizing the sample dilution at the point of measurement while still obtaining an appropriate excess of reagent and (b) as the dilution of sample and reagent are interrelated regardless of the manifold configuration (the less the sample is diluted, the more the reagent is diluted), the optimization strategy must involve maximizing the reagent concentration. This simple rule of obtaining high sensitivity does not appear to have been formulated explicitly previously.

In this paper the hypothesis that, if the single well-stirred tank model has any validity, all three of the manifold configurations should give rise to the same sensitivity is tested. Results obtained after optimization of the single, double, and reverse single line manifold configurations for maximum peak height are presented and discussed. Practical aspects concerning the use of each of the different manifolds are also discussed.

\section{EXPERIMENTAL SECTION}

Equipment. Ultraviolet and visible spectra and real-time data acquisition of flow injection peaks were obtained using a Lambda 6 UV-Vis spectrophotometer (Perkin-Elmer, Norwalk, CT). The instrument was interfaced to an IBM PS/2 (IBM, Armonk, NY) running Perkin-Elmer Computerized Spectroscopy Software (PECSS) Version 3.26. A Macintosh SE computer (Apple Inc., Cupertino, CA) with Apple File Exchange (Apple Inc.), Microsoft Excel Version 2.2a (Microsoft Corp., Redmond, WA), and Peaks Version 1.0d1.1 (Analog Digital Instruments, Milford, MA) were used for data evaluation.

Manifolds (see Figure 1) were constructed from $0.8 \mathrm{~mm}$ i.d. Teflon tubing. (Omnifit, New York, NY). All unions and end fittings were made from poly(ether ether ketone) (PEEK) (Upchurch, Oak Harbor, WA) and solutions were injected via a six-port Teflon rotary valve (Omnifit, New York, NY) with $10 \mathrm{~cm}$ of the Teflon tubing connected to each port. Reagent and carrier solutions were pumped using two Ismatec MS Reglo variable-speed pumps (Ismatec SA) which were fitted with PTFE pump tubing (Cole Palmer, Chicago, IL) of either 1.42 or $0.51 \mathrm{~mm}$ i.d. A $1 \mathrm{~cm}(18 \mu \mathrm{L})$ path length flow cell (Pye Unicam) was used. The confluence block used in the double line experiments was a Perkin-Elmer chemifold block (Perkin-Elmer).

Reagents. All solutions used in the experiments were prepared in $4 \mathrm{~g} \mathrm{~L}^{-1} \mathrm{~L}$-ascorbic acid (Fisher, Pittsburgh, PA)

(7) Lazaro, F.; Luque de Castro, M. D.; Valcarcel, M. Analyst 1984, 109, 333. (8) Valcarcel, M.; Luque de Castro, M. D. Microchem. J. 1992, 45, 189.

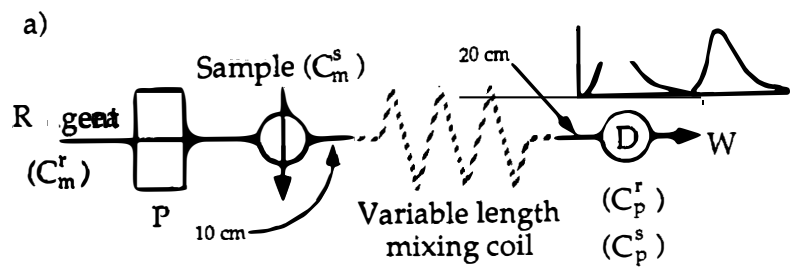

b)
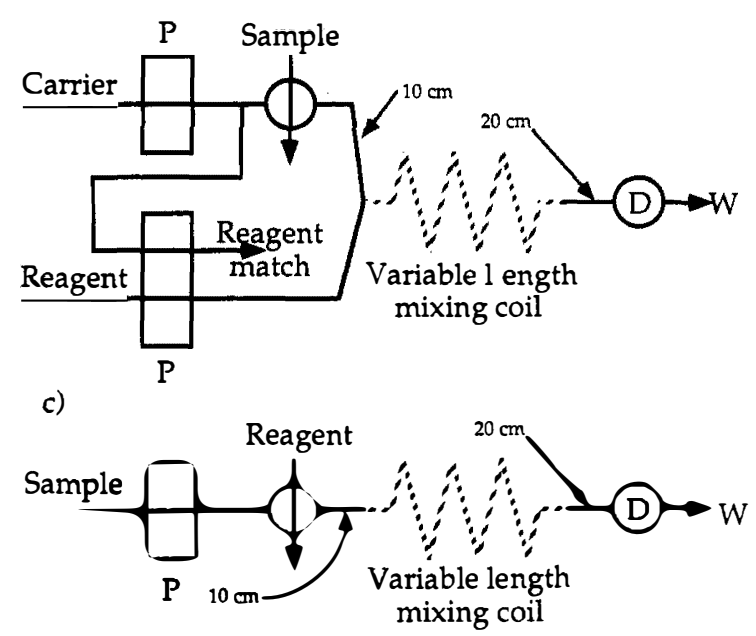

Figure 1. Manifold conflgurations used for optimization, with detector (D), pump (P), and waste (W). Lengths of tubing indicate flxed values for the injection valve and flow cell.

using doubly distilled $18 \mathrm{M} \Omega$ Epure water (Barnstead, Dubuque, IA).

For each experiment, a $2 \mu \mathrm{g} \mathrm{mL}^{-1}$ iron(II) $\left(3.58 \times 10^{-5}\right.$ M) solution was made up fresh due to its instability in aqueous solution. This was done by dilution of $1 \mathrm{~mL}$ of a $1000 \mu \mathrm{g}$ $\mathrm{mL}^{-1}$ iron(III) standard solution (Fisher) in a $500-\mathrm{mL}$ volumetric flask to which $2 \mathrm{~g}$ of ascorbic acid was added. Solutions of $o$-phenanthroline ( $o$-phen) monohydrate(Aldrich, Milwaukee, WI) were prepared according to the method of Vogel ${ }^{9}$ except that, when complete dissolution had occurred, the 1-L flask was cooled back to room temperature using cold water and $4 \mathrm{~g}$ of ascorbic acid added. The solution was then diluted to volume.

Tartrazine (Fisher) solution was prepared by dissolving $0.010 \mathrm{~g}$ in $500 \mathrm{~mL}$ of Epure water in a 1-L volumetric flask and then diluting to volume.

Procedures. The $2 \mu \mathrm{g} \mathrm{mL}^{-1}$ solution of iron(II) was analyzed off-line as a control solution for each experiment. A 5-mL aliquot of this solution was mixed with $5 \mathrm{~mL}$ of a 1 $\times 10^{-3} \mathrm{M} o$-phen solution and the absorbance measured at $510 \mathrm{~nm}$.

For the variation of manifold geometry in the single line optimization, three $80-\mathrm{cm}$ lengths of tubing were used to create knotted, coiled $(1 \mathrm{~cm}$ o.d. with axis along the direction of flow), and looped reactors for comparison with a straight length of tubing. Loops were of various sizes of one or two big circles in a horizontal plane $90^{\circ}$ to the direction of flow.

For the double line experiment, control of the flow rate ratio at the confluence point was achieved with the configuration shown in Figure $1 \mathrm{~b}$ in which the reagent match and

(9) Bassett, J.; Denney, R. C.; Jeffrey, G. H.; Mendham, J. Vogel's Textbook of Quantitative Inorganic Analysis, 4th ed.; Longman: London, 1983; p 395. 
reagent flows were the same. An increase in the pump setting produced a change in the flow rate ratio but not in the overall flow rate.

Initially a $\mathrm{T}$ configuration was used for the merging of the streams in the double line manifold (incoming streams opposite each other). However, as the mixing at the confluence point is important, a Perkin-Elmer Chemifold block was also used.

Flow rates were measured by timing the detector effluent into a $10-\mathrm{mL}$ volumetric flask. For the double line manifold, the uptake of the reagent solution was also measured. This was calculated from the weight loss of the reagent bottle over a timed period and measurement of the density of the reagent solution.

A standard set of tubing lengths was used for both the volume and manifold length variations. Lengths of 5, 10, 20, $40,50,80,100,150$, and $200 \mathrm{~cm}$ (nominal volumes 25, 50, $100,200,250,400,500,750$, and $1000 \mu \mathrm{L}$ ) were made and calibrated by weighing the water delivered from 10 replicate injections. The volume of the valve $(54 \mu \mathrm{L})$ was also measured in this way.

All peaks were collected at data acquisition rates that provided maximum definition and also allowed four or five repeat injections to be made in one run. Peak detection parameters were adjusted to provide correct identification of peaks. If this was not possible due to noise, then the inbuilt smoothing filter, a seven-point running average, was used to enhance the signal-to-noise ratio.

Calibration of the optimized configurations was carried out using $0,0.02,0.05,0.1,0.5,1$, and $2 \mu \mathrm{g} \mathrm{mL}^{-1}$ iron(II) solutions $\left(3.58 \times 10^{-7}, 8.95 \times 10^{-7}, 1.79 \times 10^{-6}, 8.95 \times 10^{-6}\right.$, $1.79 \times 10^{-5}$, and $\left.3.58 \times 10^{-5} \mathrm{M}\right)$ and a single reagent solution of concentration $1.55 \times 10^{-2} \mathrm{M}$. Each of the calibrations were carried out on the same day with the same solutions to allow direct comparison of the results.

Toexamine the extent of reaction, stopped-flow experiments were performed as necessary.

A comparison of steady-state signal and the peak maximum obtained for the injection of a $0.01 \mathrm{~g} \mathrm{~L}^{-1}$ tartrazine solution was used to quantify the reagent dispersion in the reverse single line manifold.

A comparison of the peaks obtained for the same concentration of iron (in ascorbic acid) injected into a reagent solution of $1.55 \times 10^{-2} \mathrm{M} o$-phen either with or without ascorbic acid (double line manifold) was made.

Choice of Chemical System. The reaction chosen had to fit certain criteria: First, to avoid kinetic effects it must be fast on the time scale of a typical flow injection experiment. Second, a single stable product should be formed. Third, the analyte should produce a strongly absorbing product that has an absorption maximum distinguishable from those of the reagent and analyte. Fourth, the reaction should be insensitive to $\mathrm{pH}$ over a useful working range.

After reviewing the literature, the iron(II)/o-phenanthroline (ferroin) system was chosen. The formation rate con$\operatorname{stant}^{10}$ for the $[\mathrm{Fe}(\text { phen }) 3]^{2+}$ (tris) complex is $1.3 \times 10^{19}$ $\min ^{-1}\left(25^{\circ} \mathrm{C}\right)$. The formation constant of the $1: 3$ complex is $2 \times 10^{21}$, and the reaction is known to be insensitive to $\mathrm{pH}$

(10) Lee, T. S.; Kolthoff, I. M.; Luessing, D. L. J. Am. Chem. Soc. 1948, 70, 3596.

(11) Bassett, J.; Denney, R. C.; Jeffrey, G. H.; Mendham, J. Vogel's Textbook of Quantitative Inorganic Analysis, 4th ed.; Longman: London, 1983; p 742.

\begin{tabular}{|c|c|c|c|}
\hline antavie & single & double line $e^{a}$ & reverse single line \\
\hline $\begin{array}{l}\text { reagent concn }(\mathrm{M}) \\
\text { injected vol }(\mu \mathrm{L}) \\
\text { manifold length }(\mathrm{cm}) \\
\text { flow rate }\left(\mathrm{mL} \mathrm{min}^{-1}\right)\end{array}$ & $\begin{array}{l}1.55 \times 10^{-2} \\
536 \\
80 \\
1.5\end{array}$ & $\begin{array}{l}1.55 \times 10^{-2} \\
2000 \\
100 \\
3.0\end{array}$ & $\begin{array}{l}1.55 \times 10^{-2} \\
55 \\
80 \\
1.5\end{array}$ \\
\hline
\end{tabular}

a Flow rates: carrier, $2.76 \mathrm{~mL} \mathrm{~min}{ }^{-1}$; reagent, $0.216 \mathrm{~mL} \mathrm{~min} \mathrm{~m}^{-1}$.

over range 2-9.11 Ferroin is used as a redox indicator and is stable in solution for over 6 months ${ }^{12,13}$ (if kept away from light).

Iron(III) is a possible interferent as it reacts quantitatively with $o$-phenanthroline to form a yellow polymeric o-phen/ hydroxo complex ${ }^{9}$ in aqueous solution with an absorption maximum at $360 \mathrm{~nm} \cdot{ }^{14}$ This does not interfere with the peak maximum seen at $510 \mathrm{~nm}\left(\epsilon=1.1 \times 10^{4} \mathrm{~L} \mathrm{~mol}^{-1} \mathrm{~cm}^{-1}\right)$ for the ferroin complex; however, the loss of analyte would affect the results significantly. Iron(II) was produced from a stock solution of iron(III), using excess ascorbic acid to avoid this. With excess ascorbic acid in the iron solution, the possible interference of iron(III) would be eliminated even if a significant concentration of dissolved oxygen was present. The presence of ascorbic acid in the sample was not expected to have any effect on the reaction with $o$-phen as the stability of the iron(II)/ascorbate complex ${ }^{15}$ is insignificant compared to the stability of the ferroin.

Choice of Optimization Procedure. Much interest has focused recently on the use of different optimization techniques. ${ }^{16}$ In this study there are four or five variables for each of the manifold configurations, and as studies already performed on variation of manifold parameters indicate the general effects of each on the peak height, the alternating variable search (AVS) method was used. If appropriate, a cyclic AVS procedure can be adopted. In some circumstances, this has been shown to be a highly effective procedure for searching a multiparameter factor space. ${ }^{17}$

\section{RESULTS AND DISCUSSION}

A summary of the optimized conditions is given in Table 1.

Effect of Ascorbic Acid. No substantial difference between the spectra of $o$-phen in the presence and absence of ascorbic acid was observed, although the solution containing the ascorbic acid showed a slight yellow coloration. The reaction was not affected by the presence of the ascorbic acid; therefore formation of the yellow color in the reagent was tolerated.

Single Line Manifold. The initial conditions $\left(2.4 \mathrm{~mL} \mathrm{~min}^{-1}\right.$, $110 \mathrm{~cm}, 100 \mu \mathrm{L}, 1 \times 10^{-3} \mathrm{M} o$-phen, $2 \mu \mathrm{g} \mathrm{mL}^{-1}$ iron(II) (3.58 $\left.\times 10^{-5} \mathrm{M}\right)$ ) were considered to be typical for FIA. Initial experiments were performed with the reagent stream not

(12) Schilt, A. A. Analytical Applications of 1,10-Phenanthroline and Related Compounds; Pergamon Press: New York, 1969; p 57.

(13) Greenwood, N. N.; Earnshaw, A. Chemistry of the Elements, 2nd ed.; Pergamon Press: Oxford, UK, 1986; pp 1264-1273.

(14) Harvey, A. E., Jr.; Manning, D. L. J. Am. Chem. Soc. 1952, 74, 4794

(15) Smith, R. M.; Martell, A. A. Critical Stability Constants; Plenum: New York, 1990; Vol. 2, 251.

(16) Bayne, C. K.; Rubin, I. B. Practical Experimental Designs and Optimization Methods for Chemists; VCH Publishers: Deerfield Beach, FL, 1986.

(17) Greenfield, S., Salman, S.; Thomsen, M.; Tyson, J. F. J. Anal. At. Spectrom. 1989, 4, 55. 


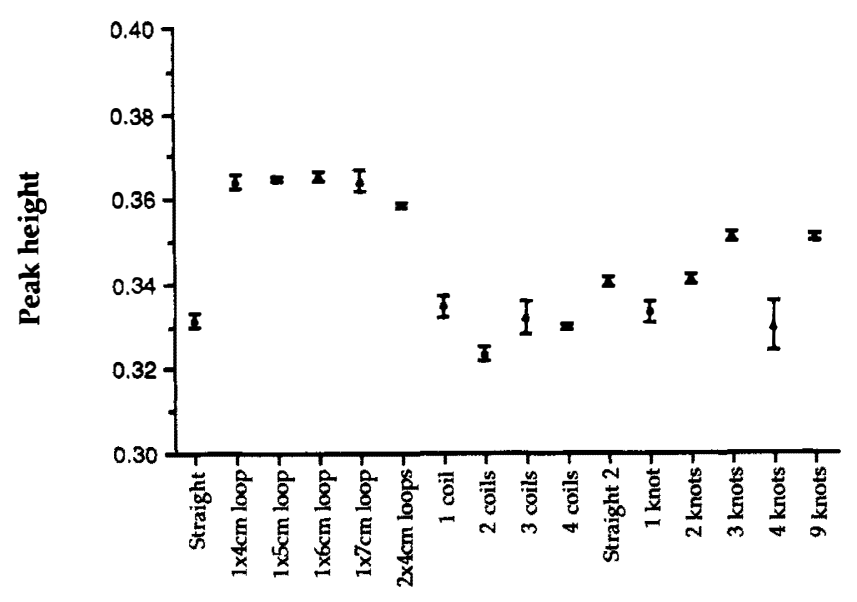

Geometry

Flgure 2. Variation of peak height with manifold geometry for the single line manifold. The same piece of tubing was used for each of the different geometries. Error bars indicate the standard deviation of the points $(n=5)$.

matched in ascorbicacid concentration to thesample. Doublet peaks due to a large refractive index peak were produced. Subsequent experiments used reagent (and carrier solutions for the double line) that contained $4 \mathrm{~g} \mathrm{~L}^{-1}$ ascorbic acid.

(a) Variation of Reagent Concentration. As the reagent concentration was increased, a transition from a doublet to a single peak of increasing height was observed as expected.

However, the use of a high reagent concentration has some practical consequences as the product signal may be swamped by a refractive index effect (as was seen in these experiments). The final reagent solution that was used was $1.55 \times 10^{-2} \mathrm{M}$ $o$-phen (below that corresponding to room-temperature saturation). No attempts were made to increase the 0 -phen concentrations available by, for example, the use of organic solvents because of possible pumping problems and the generation of even bigger refractive index effects. Thus, the general statement made in the introduction concerning reagent concentration is validated.

(b) Variation of Manifold Length. Increasing the manifold length not only increases the dispersion but also increases the residence time in the manifold (for the same flow rate). This may be important for slow reactions when the increased formation of product may more than offset the effect of increased dilution due to the additional dispersion. For the reaction between iron(II) and $o$-phen, such kinetic effects were considered to be negligible. The manifold length was only important when the manifold was very close to producing

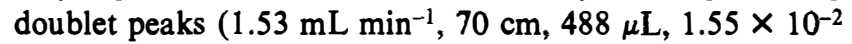
$\mathrm{M} o$-phen). Optimization in conjunction with the volume injected showed the best length to be $100 \mathrm{~cm}$, which included the tubing to the injection valve and detector (total length of $20 \mathrm{~cm}$ ).

A variation in peak height was seen when the orientation of the tubing was changed (see Figure 2). By changing the tubing from being straight to having a $6 \mathrm{~cm}$ diameter loop in it, an $8 \%$ increase in peak height was obtained. This can be attributed to the increase in radial mixing that occurs due to the secondary flow pattern developed between the tube center and the walls because of the centrifugal forces generated. ${ }^{18}$
This orientation was used for all subsequent optimization experiments (including the double line and reverse single line).

(c) Variation of Injected Volume. When the injected volume was varied, peak height increased until the formation of doublet peaks occurred for which peak height is no longer directly proportional to the sample concentration. ${ }^{19}$ The $\Delta t$ equation derived by Tyson ${ }^{20}$ for the single well-stirred tank shows that the onset of doublet peaks $(\Delta t=0)$ is, for the same reagent excess, a function of the ratio of the volume injected to the volume of the mixing chamber, which in this case is related to the length of manifold tubing. Therefore, when optimizing the manifold length, it was necessary to regularly reoptimize the volume injected in order to make full use of the single peak formation. Optimum injected volume was determined to be $536 \mu \mathrm{L}$.

(d) Variation of Flow Rate. Usually flow rate has the least affect on dispersion when working with flow injection manifolds with medium dispersion coefficients (3-10). In these experiments, minimizing dispersion is the aim and thus the flow rate becomes more important. If the stream is moving too fast, the reagent does not have time to diffuse to the center of the bolus and a doublet peak is formed. Throughout these experiments the competition between too little reaction and too much dispersion was evident. The final optimum flow rate was found to be $1.5 \mathrm{~mL} \mathrm{~min} \mathrm{~m}^{-1}$ which, combined with a manifold length of $80 \mathrm{~cm}$, gave a residence time of $15.1 \mathrm{~s}$ (from injection to first appearance of the product peak).

(e) Optimal Conditions. At the optimal conditions, the dispersion coefficient based on measurement of the product peak was found to be 1.066 . Although this value is low and produces a large reagent dilution, there is enough reagent at the peak maximum to get compete reaction.

To show that the extent of the formation of product was not limited by kinetic effects under these conditions, stoppedflow experiments were performed. No additional rise in the absorbance was seen.

It is interesting to look at the information the optimal conditions give about the reaction. From eq 1,21 it can be

$$
D_{\mathrm{r}}=\frac{D}{D-1}
$$

calculated that the dispersion coefficient of the reagent stream $\left(D_{\mathrm{r}}\right)$ at peak maximum was 16.2 . As the reagent stream concentration was originally $1.55 \times 10^{-2} \mathrm{M} O$-phen, the concentration of the reagent at the peak maximum would have been (without reaction) $9.57 \times 10^{-4} \mathrm{M}$. This indicates that the reagent is in a 9.5-fold excess at the peak maximum. However, at such low dispersion coefficient values, the reagent excess is very sensitive to small changes in $D$.

Double Line Manifold. In the case of the double line manifold, the roles of the variables are significantly different from their roles for the other two configurations.

(a) Variation of Flow Rates (and Confluence Point Dilution Factor). In the double line experiments, flow rate was found to be the most important variable. Not only does the overall

(18) Tijssen, R. Anal. Chim. Acta 1980, 114, 71

(19) Tyson, J. F. Analyst 1987, $112,523$.

(20) Tyson, J. F. Anal. Chim. Acta 1986, 179, 131

(21) Tyson, J. F.; Marsden, A. B. Anal. Chim. Acta 1988, 214, 447. 
flow rate determine the time allowed for reaction (less important), but the individual carrier and reagent flow rates determine directly the maximum sensitivity possible.

At the confluence point, the carrier is diluted by a factor of $\left(Q_{\mathrm{c}}+Q_{\mathrm{r}}\right) / Q_{\mathrm{c}}$ and the reagent by $\left(Q_{\mathrm{c}}+Q_{\mathrm{r}}\right) / Q_{\mathrm{r}}$, where $Q_{\mathrm{c}}$ and $Q_{\mathrm{r}}$ are the carrier and reagent stream flow rates, respectively. Now, if complete reaction of the analyte occurs and there is no dispersion at the center of the injected solution before the confluence point, the flow rate ratio controls the dilution of the sample and the maximum sensitivity.

Optimal overall flow rate was found to be $3.04 \mathrm{~mL} \mathrm{~min}^{-1}$. Although overall flow rate was not as important as the confluence point dilutionfactor, incomplete reaction was found to occur above a certain flow rate (dependent on the manifold length). Stopped-flow experiments showed absorbance increases up to values where the calculated dispersion coefficient was consistent with the dilution factor. This is considered to be a consequence of the nonideal mixing at the confluence point.

It was expected that the peak heights would achieve a limiting value as the flow rate decreased, but significant decreases in the peak height were observed. This possibly indicates a variation of the mixing efficiency as a function of flow rate due to channeling or segmentation at the confluence point. This is discussed further later.

(b) Variation of Reagent Concentration. In the single line experiments, the highest concentration reagent stream used was $1.55 \times 10^{-2} \mathrm{M}$ due to 0 -phenanthroline's limited solubility in water. As the necessity for the highest reagent concentration was evident before starting the double line experiments, no concentration variation was performed and $1.55 \times 10^{-2} \mathrm{M}$ $o$-phen was used throughout.

(c) Variation of Injected Volume. In order to obtain the maximum sensitivity it is necessary to let all the dilution of the sample bolus occur at the confluence point where the reagent is added. Thus, the sample volume should be large enough so that no dispersion occurs at the bolus center.

In the manifold used, the distance from the injection valve to the confluence point was set at $10 \mathrm{~cm}$ so it was necessary to inject a large volume. Initial experiments determined that a volume of $>1200 \mu \mathrm{L}$ would be needed to get flat topped peaks. A volume of $2000 \mu \mathrm{L}$ was used in subsequent experiments to allow the formation of flat topped peaks even with variation of the other parameters.

(d) Variation of Manifold Length. In principle, since the sample and the reagent are instantly mixed at the confluence point, the manifold length plays no role in the mixing of sample and reagent as is the case for the single line manifold. Length (along with the overall flow rate) is only important in governing the extent of reactions. As the reaction studied here is fast, the manifold should not need to be long, especially with a slow flow rate. However, stopped-flow experiments showed that incomplete reaction did occur when the reaction time (the time from the mixing point to the detector) was below $9 \mathrm{~s}$. It is considered that this effect arises from inhomogeneities in the mixing at the confluence point. Small pulsations in the streams produce segmentation of the carrier and reagent solutions which are homogenized by downstream flow processes. This effect has been observed previously. ${ }^{21}$

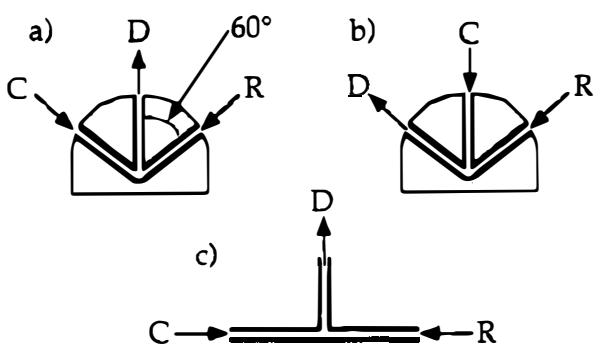

Floure 3. Confluence point varlation for the double line manifold, where $C$ is the carrier stream, $R$ is the reagent stream, and $D$ is the stream to the detector.

(e) Variation of Confluence Point Geometry. The three geometries studied are shown in Figure 3. Initially configuration a was used. This was modified to configuration $b$ in an attempt to cause more turbulence. Configuration $\mathrm{c}$, a common $\mathrm{T}$ piece, was also tried. Geometry $\mathrm{b}$ was found to give the best results; however, it is not optimal according to the findings of Clark et al. ${ }^{22}$

(f) Optimal Conditions. The optimal dilution factor, calculated from the overall flow rate of $2.98 \mathrm{~mL} \mathrm{~min}^{-1}$ and the reagent stream flow rate of $0.216 \mathrm{~mL} \mathrm{~min}^{-1}$, was found to be 1.078. The dispersion coefficient was 1.051. A comparison of the $95 \%$ confidence intervals showed that the values were not significantly different.

The optimal conditions resulted in a reaction time (time from mixing point to detector) of $9.6 \mathrm{~s}$, which is $5.5 \mathrm{~s}$ faster than the single line case. This shows the improved mixing gained by using a confluence point for reagent introduction. Residence times might be decreased further if more efficient mixing at the confluence point were possible.

Reverse Single Line Manifold. The optimum conditions found for the single line manifold were used as the starting point for the reverse line optimization.

(a) Variation of Reagent Concentration. Reagent solutions of different concentrations were injected to show the peak height variation. Even though the peaks were doublets, increasing the concentration increased the peak heights as expected. Again, the optimum concentration was $1.55 \times 10^{-2}$ $\mathbf{M}$ (this being the maximum concentration that could be used).

(b) Variation of Injected Volume. The volume injected was decreased from the initial value of $536 \mu \mathrm{L}$ until single peaks were observed (Figure 4). This occurred when the loop volume had decreased to $54 \mu \mathrm{L}$, the minimum volume which could be injected with the valve. To investigate the effect of smaller volumes, the valve was manually put in-line for only $1 \mathrm{~s}$. Although reproducibility suffered, the peak height of these injections was apparently decreased compared to those obtained with the 54- $\mathrm{LL}$ injection.

(c) Variation of Manifold Length. A variation of the manifold length was performed in conjunction with a variation in injected volume. Starting at $80 \mathrm{~cm}$ length, and $54-\mu \mathrm{L}$ injection volume, experiments were performed at points in the immediate vicinity, including at points $45^{\circ}$ to the normal search axes. The starting point was, in fact, found to be at the maximum, very close to conditions at which doublet peaks were formed.

(22) Clark, G. D.; Hungerford, J. M.; Christian, G. D. Anal. Chem. 1989, 61, 973. 


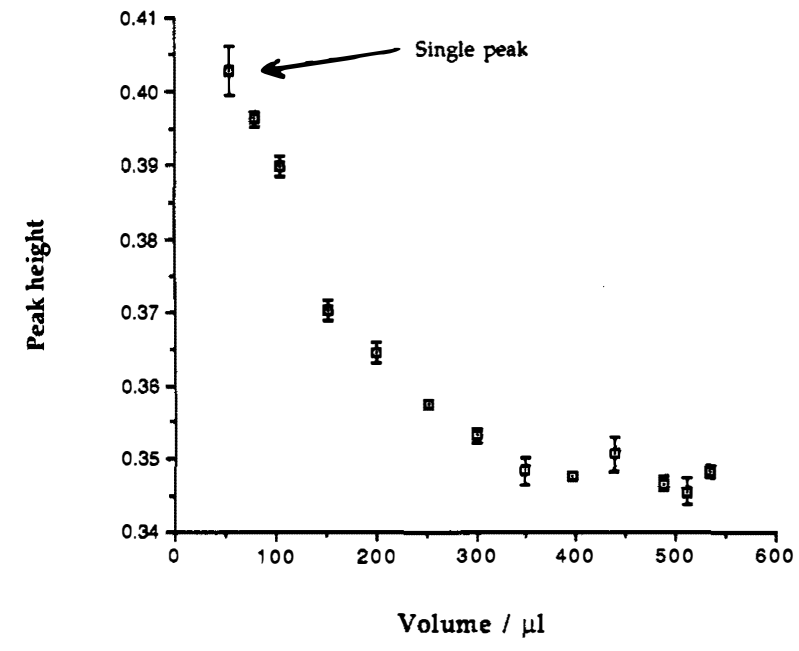

Flgure 4. Variation of peak helght with injected volume for the reverse single line manifold. All peaks are doublets except the one at $55 \mu \mathrm{L}$. Error bars indicate the standard deviation of the points $(n=5)$.

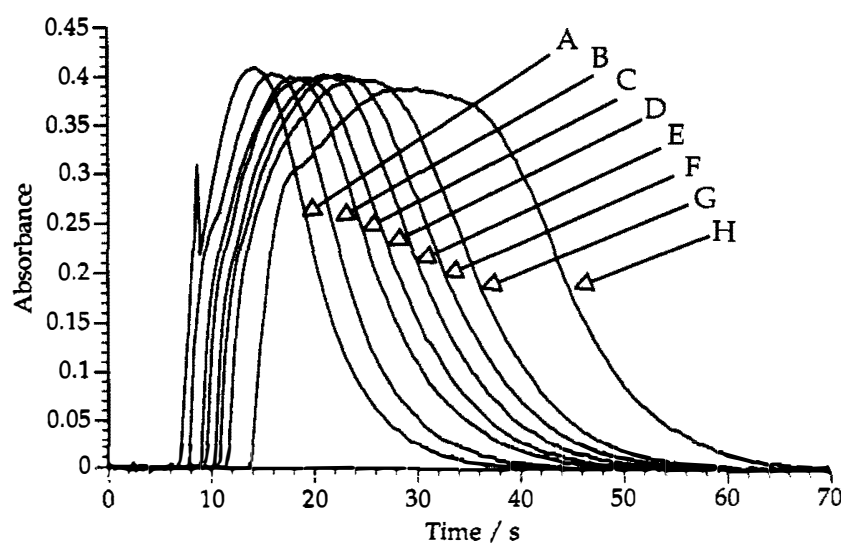

Fioure 5. Variation of peak shape with flow rate reverse single line manifold. Flow rates for $A-H$ are 2.22, 1.95, 1.73, 1.62, 1.47, 1.38, 1.27 , and $1.06 \mathrm{~mL} \mathrm{~min}^{-1}$, respectlvely.

(d) Variation of Flow Rate. Increasing the flow rate from 1.1 to $2.2 \mathrm{~mL} \mathrm{~min}^{-1}$ caused the peak height to increase until doublet peaks were formed. It was difficult to decide where double peaks were first formed (Figure 5). To ensure that a double peak was not produced, a flow rate of $1.5 \mathrm{~mL} \mathrm{~min}^{-1}$ was chosen.

(e) Optimal Conditions. The dispersion coefficient, based on measurement of the product peak, was 1.005 . When the dispersion coefficient was calculated from the peak profile obtained for the injection of the tartrazine solution, it was found that the dispersion coefficient was 4.2. The sample dispersion coefficient was calculated to be 1.313 (eq 1), which is significantly different from the value obtained experimentally. However an examination of the concentration/time profiles (see Figure 6 ) of the sample, reagent, and product shows that the best sample-to-reagent ratio (for the maximum formation of product) does not occur at the sample peak minimum. Because the sample is diluted more in the middle than at the ends, and the reagent is in excess, the best ratio occurs on the tail of the peaks. This shows one of the distinct differences between the normal and reverse single line manifolds.

Comparison of Sensitivities. Three different solutions were prepared at each of seven concentrations. Each of the

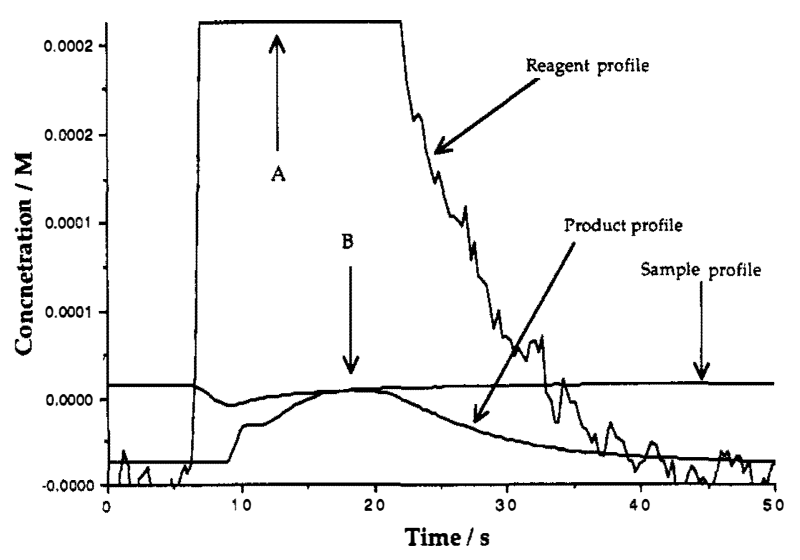

Floure 6. Graph of reagent, sample, and product profiles for a typlcal peak in the reverse line manifold. The dispersion minimum for the reagent occurs at (A), but the product dispersion minimum occurs at (B). The product peak absorbance profile was converted to concentration using the molar absorptlitty of $\left[\mathrm{Fe}(a-p h e n)_{3}\right]^{2+}$ at $510 \mathrm{~nm}$. The reagent and sample profiles were generated using the initial concentrations of sample and reagent and the dlsperston coefflcient at each point on the peak (from the steady-state absorbance and the product peak absorbances at each point). The values were then scaled appropriately.

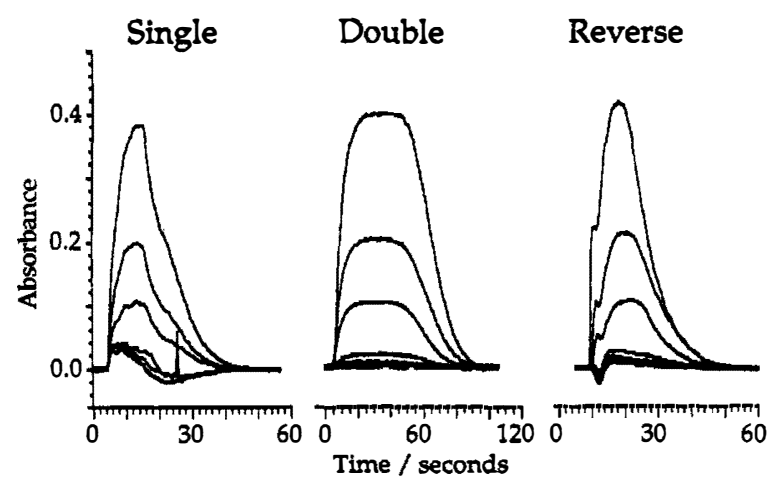

Figure 7. Comparison of the peak shapes from the callbration of the three manlfolds. Concentrations are $0,0.02,0.05,0.1,0.5,1$, and 2 $\mu \mathrm{g} \mathrm{mL}{ }^{-1}$ iron(II).

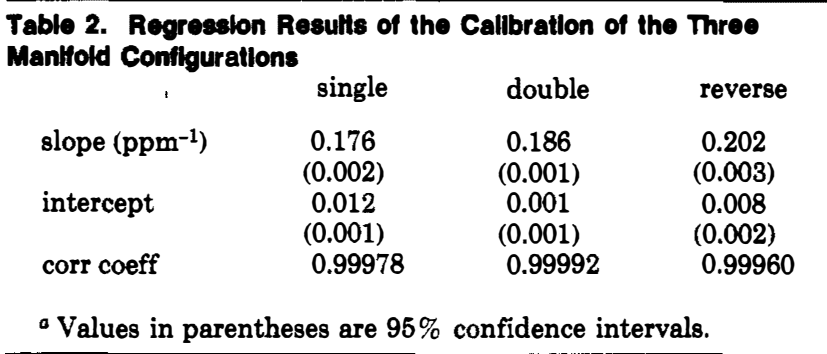

calibration regression lines was based on 63 points (three injections of each solution) giving 61 degrees of freedom.

Table 2 shows the results of the regression analysis with the confidence intervals shown in parentheses as calculated from formulas found in Miller and Miller. ${ }^{23}$ Although the sensitivities are similar, there are significant differences at the $95 \%$ confidence level.

None of the intercepts is zero. For the single line manifolds, this is the result of a refractive index effect as can be seen in Figure 7. This effect is an inherent feature of single line manifolds as usually the reagent stream will have a significantly

(23) Miller, J. N.; Miller, J. M. Statistics for Analytical Chemists; Ellis Horwood: Chichester, UK, 1984; p 93. 
different refractive index from that of the sample, especially if the reagent concentration has been maximized. The double line manifold does not suffer from this because the mixing at the confluence point produces a constant reagent concentration, and if large sample volumes are used to produce "flat-topped" peaks, there are no other concentration gradients in the flow cell, which could be responsible for refractive index peaks.

\section{CONCLUSION}

There is no basis for the notion that certain types of design of flow injection manifold have substantially higher sensitivity than others. The single well-stirred tank model provides an adequate description for these three common FI manifold configurations as the optimized manifolds give rise to similar sensitivity. The optimum dispersion coefficients (below 1.1) are considerably lower than normally encountered in reports of manifold optimization studies. This is possibly a consequence of not adopting the requirement to maximize the reagent concentration(s). Often literature reports are somewhat vague about the figure of merit to be optimized, and although maximum sensitivity is often implied, in practice other considerations such as throughput or reagent consumption are taken into account. For molecular absorption spectrometry, it is also clear from these results that the double line manifold is more useful than the other two. Although the volume of sample required is high compared to the single line case, this is more than outweighed by the small reagent consumption, and the absence of a refractive index peak. This conclusion may not be valid for other spectroscopictechniques which are less susceptible to refractive index effects.

The results of this study show that the manifold configurations will have different detection limits because of the

(24) Toei, K.; Hiraishi, S.; Nakagawa, T.; Zenki, M. J. Flow Injection Anal. 1993, 10,94 . practical considerations arising mainly from the various noise sources. One of the most severe is that accompanying the refractive index effect of the single line manifolds, and it is concluded that the best detection limits will be obtained with the double (or multiline configuration). A second problem which has attracted relatively little attention is that of the difficulty of producing efficient mixing at confluence points. The detection limit for the determination of iron in this study was $10 \mathrm{ng} / \mathrm{mL}$; however, a recent report ${ }^{24}$ of the determination of iron by the chemistry used here showed that, with appropriate attention to the problem of mixing noise (and some electronic signal processing), detection limits of less than $1 \mathrm{ng} / \mathrm{mL}$ can be obtained.

The small differences between thesensitivities indicate that there are some limitations to the application of the model. The model assumes that all hydrodynamic processes are the same flow for each manifold, but obviously the predominant mechanism of mixing for the single line cases (that of diffusion across the gradients produced by the laminar flow) is quite different from that of the double line case (turbulence at a confluence point). Also, there are various secondary processes which are not incorporated into the model but which are significant, such as the flow patterns produced in coiled tubes and those due to differences in the diffusion coefficients of the sample and reagent. 